\section{Estudo \\ cobebate}

em Cestão

Planejamento
Revista Estudo \& Debate, Lajeado, v. 24, n. 1, 2017. ISSN 1983-036X

DOI: http://dx.doi.org/10.22410/issn.1983-036X.v24ila2017.1180

\title{
RELAÇÃO ENTRE PROFUNDIDADE ÓPTICA DE AEROSSÓIS E RADIAÇÁO FOTOSSINTETICAMENTE ATIVA E GLOBAL NO CERRADO MATO-GROSSENSE
}

\author{
Jonathan Willian Zangeski Novais ${ }^{1}$, Franciele Bomfiglio Santanna ${ }^{2}$, \\ Paulo Henrique Zanella de Arruda ${ }^{3}$, Osvaldo Alves Pereira ${ }^{4}$, Rosemery Dutra ${ }^{5}$
}

\begin{abstract}
Resumo: As ações antrópicas, em especial a queima de biomassa, são as principais responsáveis pelo envio de aerossóis para a atmosfera, e esse particulado exerce influência sobre o balanço de energia e os ciclos hidrológicos, fazendo com que o seu estudo seja inerente à compreensão desses processos. Cientes disso, o objetivo deste estudo foi obter uma relação entre a profundidade ótica dos aerossóis (POA) e a radiaçáo solar incidente em área de Cerrado em MT. Utilizou-se dados de POA coletados de jan/2010 a dez/2012, obtidos pela rede AERONET (Aerosol Robotic Network - NASA). Esses dados foram analisados em conjunto com dados de focos de queimadas, sendo possível encontrar altos valores de POA nas estações secas, chegando a uma média de 3,8 em 2010. Tanto a radiação global $\left(\mathrm{R}_{\mathrm{g}}\right)$ quanto a radiação fotossinteticamente ativa (RFA) tem correlaçấo significativa ( $\mathrm{p}<0.01$ para 2011 e 2013, $\mathrm{p}<0.05$ para 2011) com POA, e altos valores de POA correspondem a uma quantidade significativa de particulados na atmosfera, diminuindo a intensidade da radiação solar e provocando alteraçóes de sua distribuiçáo no sistema superfície-atmosfera.
\end{abstract}

Palavras-chave: Radiação solar. AERONET. Balanço de radiação. Queimadas.

\section{RELATIONSHIP BETWEEN AEROSOLS OPTICAL DEPTH AND PHOTOSYNTHETICALLY AND GLOBAL RADIATION IN A SAVANNA OF MATO GROSSO, BRAZIL}

Abstract: The anthropic activities, particularly the biomass burning, are the main responsible source of aerosols to the atmosphere, and this particulate matter influences the regional energy balance and hydrological cycle, studying this is inherent to the understanding of these processes. The goal of this study is obtain a relationship

1 Universidade de Cuiabá - UNIC.

2 Universidade de Cuiabá - UNIC.

3 Universidade Federal de Mato Grosso.

4 Universidade de Cuiabá - UNIC.

5 Universidade de Cuiabá - UNIC. 
between the aerosol optical depth (AOD) and the components of solar radiation in a Cerrado (Brazilian savanna) area in Mato Grosso state. AOD data was collected from Jan/2010 to Dec/2012, obtained from the AERONET network (AErosol RObotic NETwork - NASA). These data were analyzed in conjunction with vegetation fires data, and is possible to find high AOD values in the dry season, reaching an average of 3.8 in 2010. Both, the global radiation $(\mathrm{Rg})$ and the photosynthetic active radiation (PAR) has a significant correlation ( $p<0.01$ for 2011 and 2013, $p<0.05$ for 2011) with AOD, and high AOD values correspond to a significant amount of particulate matters in the atmosphere, reducing the intensity of solar radiation and causing changes in their distribution in the surface-atmosphere system.

Keywords: Solar radiation. AERONET. Radiation balance. Fires.

\section{INTRODUÇÃO}

Dentre as atividades antropogênicas, as queimadas são as principais responsáveis pela liberação de partículas de aerossóis para o ar e essas partículas interagem com a radiação solar afetando o balanço de energia, bem como alterando o ciclo hidrológico local (PROCÓPIO et al., 2004; ROCHA, 2011). Dessa forma, entender os processos naturais que regulam a composição da atmosfera se torna fundamental para que se possa desenvolver uma estratégia de desenvolvimento sustentável (ARTAXO et al., 2005).

As partículas de aerossóis de queimadas são bastante complexas em suas composiçóes química, porque sua formaçáo depende da temperatura do fogo, das condiçóes micrometeorológicas e também do tipo de material que está sendo queimado. As grandes emissóes de gases e partículas em períodos de seca provenientes das queimadas alteram profundamente a composição da atmosfera amazônica na maior parte de sua área. As concentraçóes de partículas de aerossóis e gases traço aumentam por fatores de 2 a 8 em grandes áreas, afetando a dinâmica natural de uma série de processos atmosféricos (ARTAXO et al., 2005). Essas partículas podem se unir a outros componentes químicos presentes na atmosfera liberados por outras fontes e formar uma nova partícula, as partículas secundárias, ambas influenciando direta ou indiretamente no clima (YÁÑEZ-SERRANO et al., 2016).

Quando um feixe de luz monocromático de radiação atravessa um meio absorvente, o mesmo é atenuado, podendo ocorrer tanto por espalhamento quanto por absorção, ocorrendo excitação de espécies químicas (HARRIS, 2008). Essa absorção depende da estrutura das espécies atômicas, ou moleculares envolvidas, assim algumas frequências de radiação são seletivamente retidas, sendo o feixe transmitido menos intenso que o feixe incidente (MOREIRA et al., 2016).

A concentração de ozônio, um gás importante para a saúde de florestas passa de cerca de 12 partes por bilhão em volume (ppb) (concentração típica ao meio do dia na estação chuvosa) para valores em regióes fortemente impactadas por queimadas de até $100 \mathrm{ppb}$, nível que pode ser fitotóxico para a vegetação. O balanço de radiação é fortemente afetado, com uma perda líquida de até $70 \%$ da radiaçáo fotossinteticamente ativa na superfície (ARTAXO et al., 2005; REDDINGTON et al., 2016).

No processo indireto, o aerossol pode atuar como núcleo de condensação de nuvens, alterando propriedades das nuvens como refletância, tempo de vida, fase, tamanho e precipitação (KOREN et al., 2007; ROCHA; YAMASOE, 2013). 
No processo direto, as camadas de aerossóis absorvem radiação solar, gerando um aquecimento nessa camada de ar e resfriando nas inferiores, assim como espalhando parte da radiação solar de volta ao espaço. Desse modo, a radiação incidente em superfície diminui causando alteraçóes no perfil termodinâmico da atmosfera, modificando os fluxos de $\mathrm{CO}_{2}$ calor latente e sensível, o processo de formaçáo de nuvens, altura da camada limite, taxas de evaporação e os padrões de circulação regional (PROCÓPIO et al., 2004). Ocorre também, um aumento da fração difusa da radiação solar (YAMASOE; ROSÁRIO, 2009), que, particularmente na região espectral fotossinteticamente ativa, pode aumentar a capacidade de fotossíntese, pois a radiaçáo penetra de modo mais eficiente no dossel e atinge folhas sombreadas (YAMASOE et al., 2006). Por exemplo, nuvens de fumaça da queima de biomassa, provocam aumentar da produtividade das planta, através do aumento da quantidade de radiação difusa (OLIVEIRA et al., 2007; DOUGHTY et al., 2010; RAP et al., 2015).

As partículas de aerossóis são criticamente importantes nos ciclos biogeoquímicos, por ser um meio de transporte eficiente para micronutrientes essenciais para o ecossistema, tais como cálcio $(\mathrm{Ca})$, fósforo $(\mathrm{P})$ e nitrogênio $(\mathrm{N})$, entre outros compostos (ARTAXO et al., 2006).

Todos os dias são lançados na atmosfera gases poluentes por fontes naturais ou antropogênicas que vêm modificando o funcionamento de vários ecossistemas naturais e urbanos pelo mundo (SILVA JR.; ANDRADE, 2013). Essas modificaçóes são causadas na maioria das vezes pela exploração dos recursos naturais, transformaçôes agrícolas e desenvolvimento urbano e industrial. $\mathrm{O}$ cerrado brasileiro constitui-se na maior savana neotropical, com uma área estimada em cerca de 200 milhóes de hectares. Cerca de $80 \%$ da superfície do Cerrado já foi convertida em pastagens cultivadas, lavouras diversas e áreas urbanas (PRIMACK; RODRIGUES, 2001), causando a destruição, fragmentação e isolamento de ambientes naturais do Bioma.

Apesar da falta de registros a longo prazo, existe ampla evidência de que as savanas, de um modo geral, estẫo sujeitas a grandes mudanças provocadas pelo fogo, seca, herbivoria, intervenção pelo homem, pastagem, agricultura, remoção de árvores para carvão, entre outras. Em muitas partes do mundo, as atividades antrópicas constituem-se na maior fonte de distúrbio para as savanas (FROST et al., 1986), e mesmo assim, estas continuam a existir e a se estabelecer após virtual eliminaçáo em muitas áreas e tudo isto aponta para um alto grau de resiliência (WALKER; NOY-MEIER, 1982).

O Cerrado tem passado por mudanças significativas na última década devido ao intenso processo de desmatamento (REZENDE et al., 2005). Uma vez que as queimadas ainda são vistas como a melhor forma de manejo de pastagens e contenção de espécies nativas ou invasoras, pois, apresentam custo financeiro mínimo, sendo praticada no Brasil e no Estado de Mato Grosso (PERON; EVANGELISTA, 2004; SILVA et al., 2004).

Um estudo da profundidade óptica dos aerossóis e micrometeorologia em séries temporais no cerrado mato-grossense, possibilita o entendimento da interaçâo das partículas com radiação solar, seja com a radiação global, todo o espectro, ou somente com a radiação fotossinteticamente ativa, que representa o somatório de fótons incidentes entre 0,4 a 0,7 $\mu \mathrm{mol} \mathrm{m} \mathrm{s}^{-2} \mathrm{~s}^{-1}$ (MONTGOMERY; CHAZDON, 2001). 
Assim objetiva-se analisar a relação da profundida óptica dos aerossóis com a radiação global e radiação fotossinteticamente ativa (RFA) em área de cerrado nos anos de 2010, 2011 e 2012.

\section{MATERIAIS E MÉTODOS}

\section{1 Área de estudo}

A pesquisa foi realizada na Fazenda Miranda no município de Cuiabá, capital do estado de Mato Grosso. A fazenda está localizada em 1543’ Sul e 5604’ Oeste, com altitude de $157 \mathrm{~m}$ acima do nível do mar (FIGURA 1).

Figura 1 - Localização da Fazenda Miranda em Cuiabá - MT

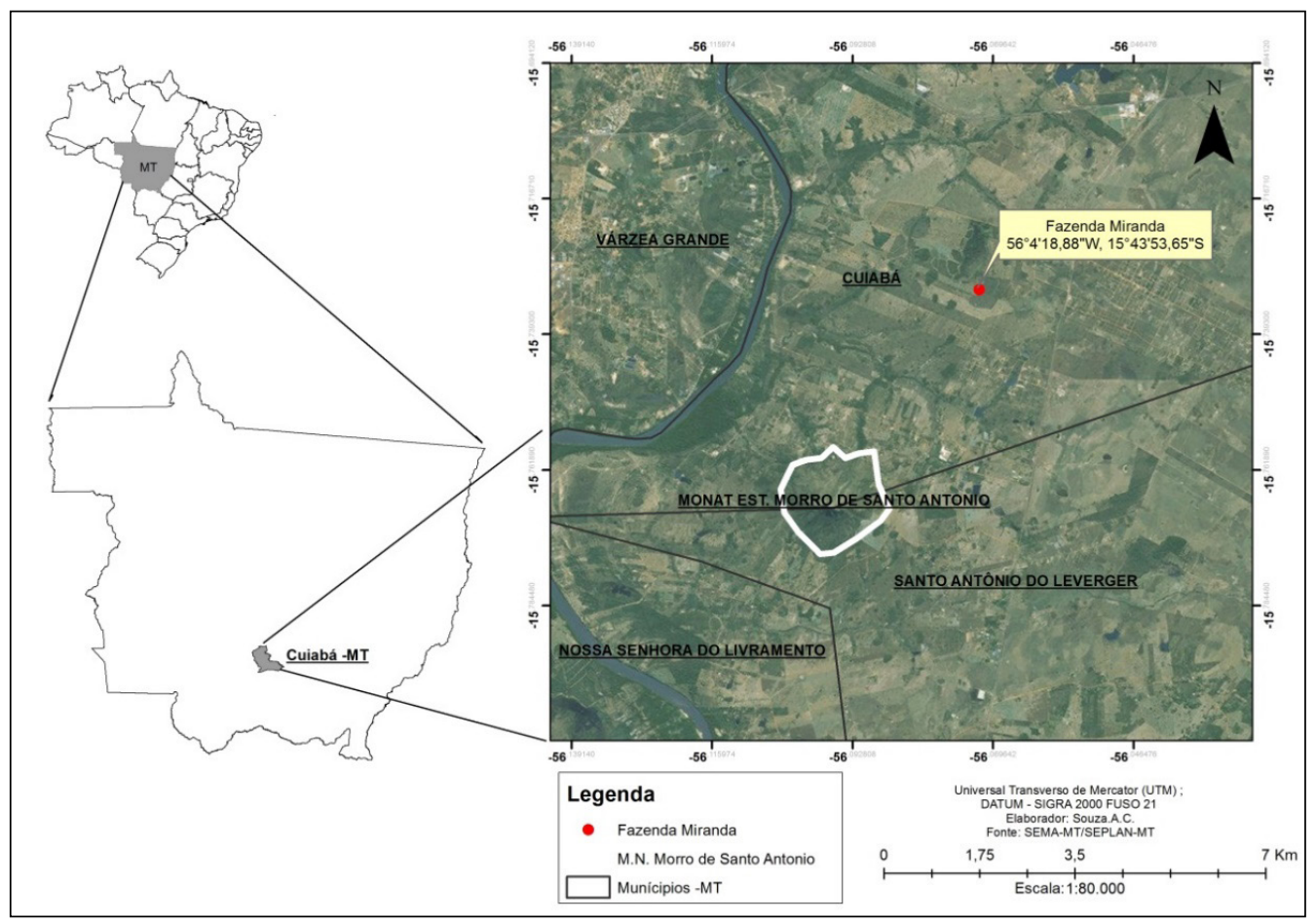

O clima regional é classificado como Aw, tropical semiúmido, segundo a classificação climática de Köppen (1948). Possui quatro a cinco meses secos e duas estaçóes bem definidas, uma seca (outono-inverno) e outra úmida (primavera-verão) (NOVAIS et al., 2015a). Em média, as temperaturas mínimas ao longo dos anos são de $5^{\circ} \mathrm{C}$ e as máximas chegam a $41^{\circ} \mathrm{C}$. O índice pluviométrico diferencia-se de forma significativa durante as estaçóes, pois em sua maioria o inverno é bastante seco e o verão bastante úmido. A média na região é de 1500 mm/ano (SAMPAIO, 2006; NOVAIS et al., 2016). 
A vegetação do local é tipicamente de cerrado - campo sujo, apresentando floresta decídua na encosta dos morros e floresta de galeria ao longo dos rios, porém em alguns trechos a vegetação é típica de áreas alagadas (COUTINHO, 1990; SILVA, 2007). O solo da área em que a pesquisa foi desenvolvida é caracterizado por ser pouco espesso, imperfeitamente drenado, concrecionário e com superfície cascalhenta (Plintossolo Pétrico), podendo ocorrer locais com a presença de solos Litólicos Distróficos (EMBRAPA, 1999). A área do estudo encontra-se caracterizada pela dominância da vegetação herbácea que surgiu depois da derrubada parcial da vegetação original. Observa-se apenas a cobertura parcial da vegetação no solo em locais onde a superfície é caracterizada pela textura cascalhenta.

\subsection{Aquisição de dados}

Neste estudo utilizou-se 3 anos de dados micrometeorológicos de profundidade ótica dos aerossóis e de focos de queimadas coletados de forma contínua de janeiro de 2010 até dezembro de 2012.

Os dados de profundidade ótica dos aerossóis foram coletados por um radiômetro espectral CE318 (Cimel Electronique, França) instalado em um sítio experimental próprio, localizado a 10 metros da torre micrometeorológica. Estes dados são coletados e enviados para NASA, e disponibilizados na rede global de monitoramento de aerossóis por sensoriamento remoto AERONET (Aerosol Robotic Network), disponíveis na página <http://aeronet.gsfc. nasa.gov>. Os equipamentos da AERONET são mantidos pelo Sistema de Observação da Terra da NASA/GSFC (National Aeronautics and Space Administration/Goddard Space Flight Center). Os arquivos de dados da rede AERONET são divididos em três níveis de qualidade: nível 1.0 para os dados brutos, nível 1.5 para dados sem a contaminação de nuvens e nível 2.0 cuja qualidade é certificada pela rede (HOLBEN et al., 1998;), ao todos os dados são disponibilizados para 8 bandas diferentes, 340, 380, 440, 500, 670, 870, 940 e $1020 \mathrm{~nm}$. Neste trabalho utilizou-se os dados de nível 2.0 para o comprimento de onda $500 \mathrm{~nm}$ (máximo do fluxo radiativo solar no topo da atmosfera).

Os dados referentes aos números de focos de queimadas e incêndios no Estado de Mato Grosso foram obtidos através da página do Instituto Nacional de Pesquisas Espaciais - INPE (<http://www.inpe.br/queimadas >). Para gerar estes dados, são utilizados todos os satélites que possuem sensores óticos operando na faixa termal-média de $4 \mu \mathrm{m}$ e que o INPE tenha acesso.

Os dados micrometeorológicos foram coletados por sensores instalados em uma torre micrometeorológica com 20 metros de altura, instalada pelo projeto "Implantaçáo de Postos de Observação de Gases -Traço e de Aerossóis na Atmosfera em Mato Grosso" (MCT-CNPq-CT Infra CT Energ n. 07- 2006). Os dados micrometeorológicos foram adquiridos pelos sensores: Saldo de radiaçấo $\left(\mathrm{R}_{\mathrm{n}}\right)$ - NR LITE (Kipp e Zonen Delft, Inc., The Netherlands) instalado a $4 \mathrm{~m}$ de altura; Radiação global incidente $\left(\mathrm{R}_{\mathrm{g}}\right)$ piranômetro LI-200X-L (Campbell Scientific, Inc., USA) a 4m; Temperatura do ar ( $\left(\mathrm{T}_{\mathrm{ar}}\right)$ e umidade relativa do ar (UR) - 3 termohigrômetros HMP 45AC (Vaisala, Inc., Helsinki, Finland) a 5, 10 e 18m; Precipitação pluviométrica (Ppt) - pluviômetro de báscula - TR-525M rainfall sensor (Texas Eletronics, Inc., USA) a 5m; Radiação RFA - sensor quantum da Li-Cor, LI 
900SB; Umidade do solo - Reflectômetro CS616 (Campbell Scientific, Inc., USA) à 20cm de profundidade.

\section{RESULTADOS E DISCUSSÃO}

\subsection{Micrometeorologia do local}

O comportamento das variáveis micrometeorológicas nesta região é distinto ao longo do ano, justificando assim uma divisão sazonal conforme o regime de chuvas (FIGURA 2).

Figura 2 - Média quinzenal da intensidade de Radiação global $\left(\mathrm{R}_{\mathrm{g}}\right)$, saldo de radiação $\left(\mathrm{R}_{\mathrm{NET}}\right)$, Fluxo de radiação fotossinteticamente ativa (RFA), temperatura do ar $\left(\mathrm{T}_{\mathrm{ar}}\right)$, umidade relativa do ar (UR), umidade do solo (US) e precipitação acumulada (PPT) para as estaçóes seca (área cinza) e chuvosa (área branca) para os anos de 2010, 2011 e 2012

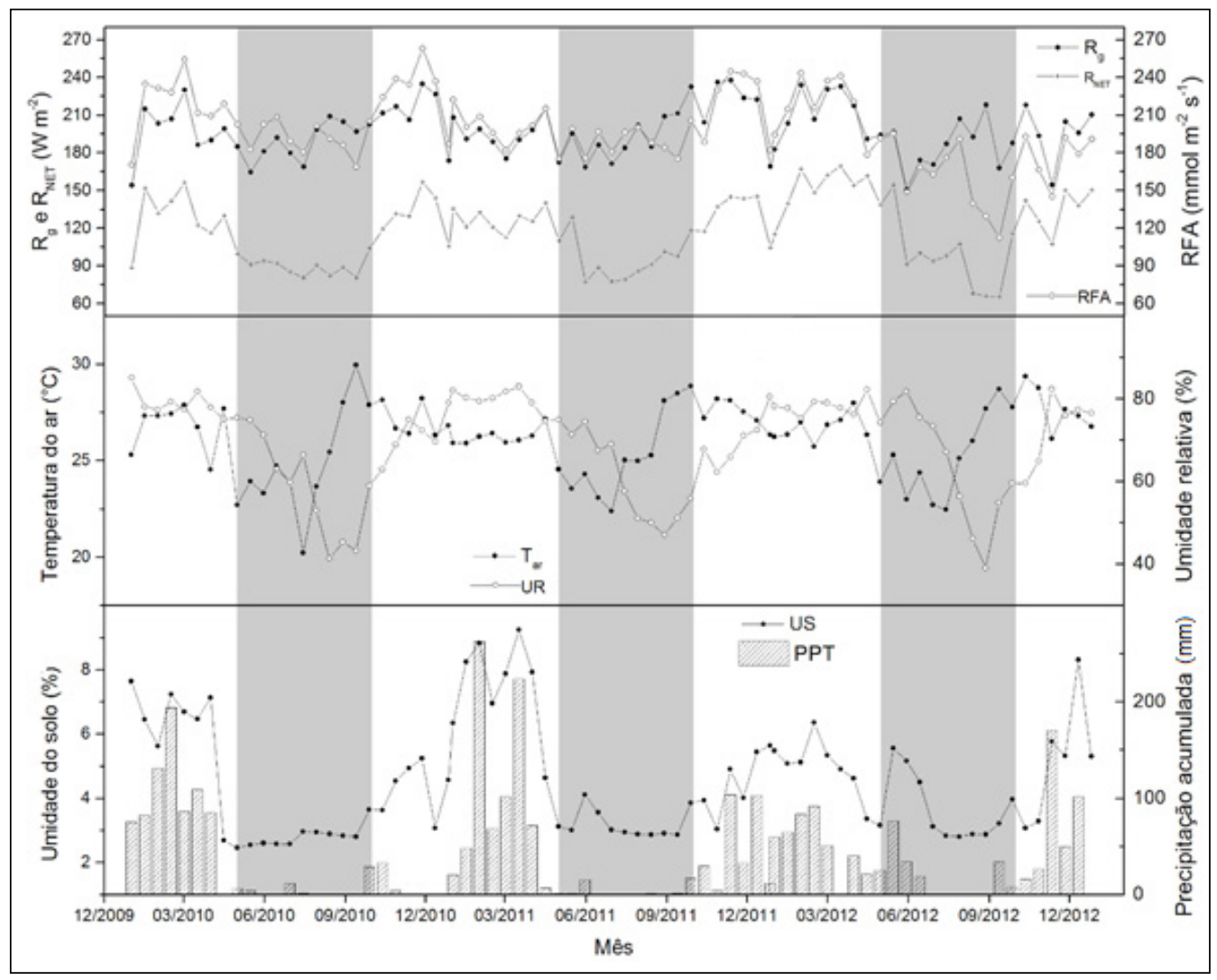

A radiação solar global $\left(\mathrm{R}_{\mathrm{g}}\right)$, variou de aproximadamente $160 \mathrm{Wm}^{-2}$ (valor mínimo) no período de seca a $240 \mathrm{Wm}^{-2}$ no período de chuva (FIGURA 2). O saldo de radiação $\left(\mathrm{R}_{\mathrm{NET}}\right)$ variou de aproximadamente $62 \mathrm{Wm}^{-2}$ na estação seca a $170 \mathrm{Wm}^{-2}$ na estação de chuva. Carrilho Sobrinho (2011), encontrou os valores de radiação solar global incidente $\left(\mathrm{R}_{\mathrm{g}}\right) 42$ $\mathrm{Wm}^{-2}$ (valor mínimo) e 305,78 $\mathrm{Wm}^{-2}$ (valor máximo) para o mesmo local e períodos. Já 
Novais et al. (2016), encontraram para o pantanal mato-grossense valores médios máximos próximos a $340 \mathrm{Wm}^{-2}$, e mínimos $140 \mathrm{Wm}^{-2}$. Durante o período chuvoso, final da primavera ao início do outono, o hemisfério sul recebe maior quantidade de radiação solar, mas os valores de $\mathrm{R}_{\mathrm{g}}$ não se alteram em comportamento. Isso se deve ao fato da cobertura do céu por nuvens ser muito maior nesta época, o que limita a quantidade de radiaçáo incidente na superfície do solo, mas $\mathrm{R}_{\mathrm{NET}}$ se mantem maior. A redução nos valores de $\mathrm{R}_{\mathrm{g}}$ e $\mathrm{R}_{\mathrm{NET}}$ durante a estaçáo seca se devem ao efeito inverso, pois nesta época o hemisfério sul recebe uma menor quantidade de radiação solar. Essa diminuição de radiação solar influencia diretamente na energia disponível, uma vez que a diminuição de radiação diminui a parcela de emissão da atmosfera do balanço de ondas. A profundidade ótica dos aerossóis devido as queimadas na região também corroboram com a cobertura do céu e consequentemente menos radiaçáo atinge a superfície.

Fez-se a razão entre RFA e Rg para os períodos seco e chuvosos analisados, conforme Tabela 1:

Tabela 1: Médias sazonais da razão da radiação fotossinteticamente ativa (RFA) pela radiação global (RG), para os anos de 2010, 2011 e 2012

\begin{tabular}{cc}
\hline Período & RFA/Rg $(\mathbf{m m o l} / \mathbf{J})$ \\
\hline chuvoso - 2010 & 1,09 \\
\hline seco - 2010 & 1,05 \\
\hline chuvoso - 2010/2011 & 1,07 \\
\hline seco - 2011 & 1,02 \\
\hline chuvoso - 2011/2012 & 1,05 \\
\hline seco - 2012 & 0,68 \\
\hline chuvoso -2012 & 0,93 \\
\hline
\end{tabular}

As variações da radiação fotossinteticamente ativa (RFA) acompanharam os padróes de radiação global, observado pela pouca variação da razão RFA/Rg entre os meses. Os menores valores ocorreram nos meses de seca, conforme as áreas em cinza, e maiores valores nos períodos chuvosos, conforme áreas claras, Figura 2. Novais et al. (2015b) encontraram o mesmo padrão para radiação solar global para o Pantanal mato-grossense.

As maiores médias de temperatura do ar $\left(\mathrm{T}_{\mathrm{ar}}\right)$ ficaram entre 28 e $30^{\circ} \mathrm{C}$ no mês de setembro para todos os anos estudados. $\mathrm{Na}$ estação de chuva a $\mathrm{T}_{\mathrm{ar}}$ máxima foi de $27^{\circ} \mathrm{C}$ nos

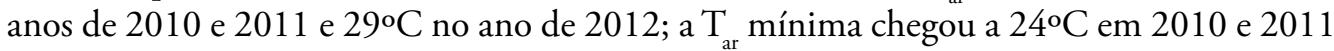
e $26^{\circ} \mathrm{C}$ em 2012. Rodrigues et al. (2011), encontrou para o mesmo local, uma temperatura média de $25^{\circ} \mathrm{C}$ durante toda a estação seca. Este período apresenta alta amplitude na temperatura, conforme Figura 2, pois é na seca que ocorre a entrada das frentes frias na região e a baixa umidade relativa do ar contribui para esta variação, já que a água é um importante composto na regulação térmica.

Durante a estação chuvosa a umidade relativa do ar (UR) chegou a $80 \%$, enquanto que na estação seca chegou a $40 \%$ entre os meses de agosto e setembro. Os baixos valores 
da UR na estação seca mostram que havia pouca disponibilidade de água disponível ao ecossistema neste período.

Durante a estação chuvosa, os maiores valores de precipitação acumulada encontrados foram no mês de fevereiro para os anos de 2010 e 2011 com 200 e $260 \mathrm{~mm}$ respectivamente relacionados com alta umidade do solo. Na estação seca a umidade do solo chegou a 2,3\% em 2010 e 3\% em 2011 e 2012. Ao analisar esta relação observa-se que com a diminuição da precipitação no período da seca, ocorre uma diminuiçáo na umidade do solo, ou seja, com a evaporação da água pela radiaçáo solar nesse período o solo perde a umidade tornando-se mais seco, à medida que inicia o período chuvoso o solo vai absorvendo água da chuva e assim aumentando a umidade que chegou a $9 \%$.

\subsection{Profundidade óptica dos aerossóis e focos de queimadas}

As médias diárias da POA e quantidade total mensal dos focos de queimadas para as estaçóes seca e chuvosa para os anos 2010, 2011 e 2012, estấo apresentados na Figura 3. O maior valor para POA foi 3,8 registrado no mês setembro (2010), mês que corresponde à estação seca. Neste período ocorrem os maiores índices de focos em MT, emitindo grandes quantidades de partículas de aerossóis para a atmosfera, período este que a temperatura do ar é bastante elevada e a umidade relativa está bastante baixa. Palácios (2014), para cerrado, encontrou valores diários acima de 3,5 no ano de 2010 para POA.

Figura 3 - Média diária da POA e quantidade total mensal dos focos de queimadas para as estaçóes seca e chuvosa para os anos 2010, 2011 e 2012

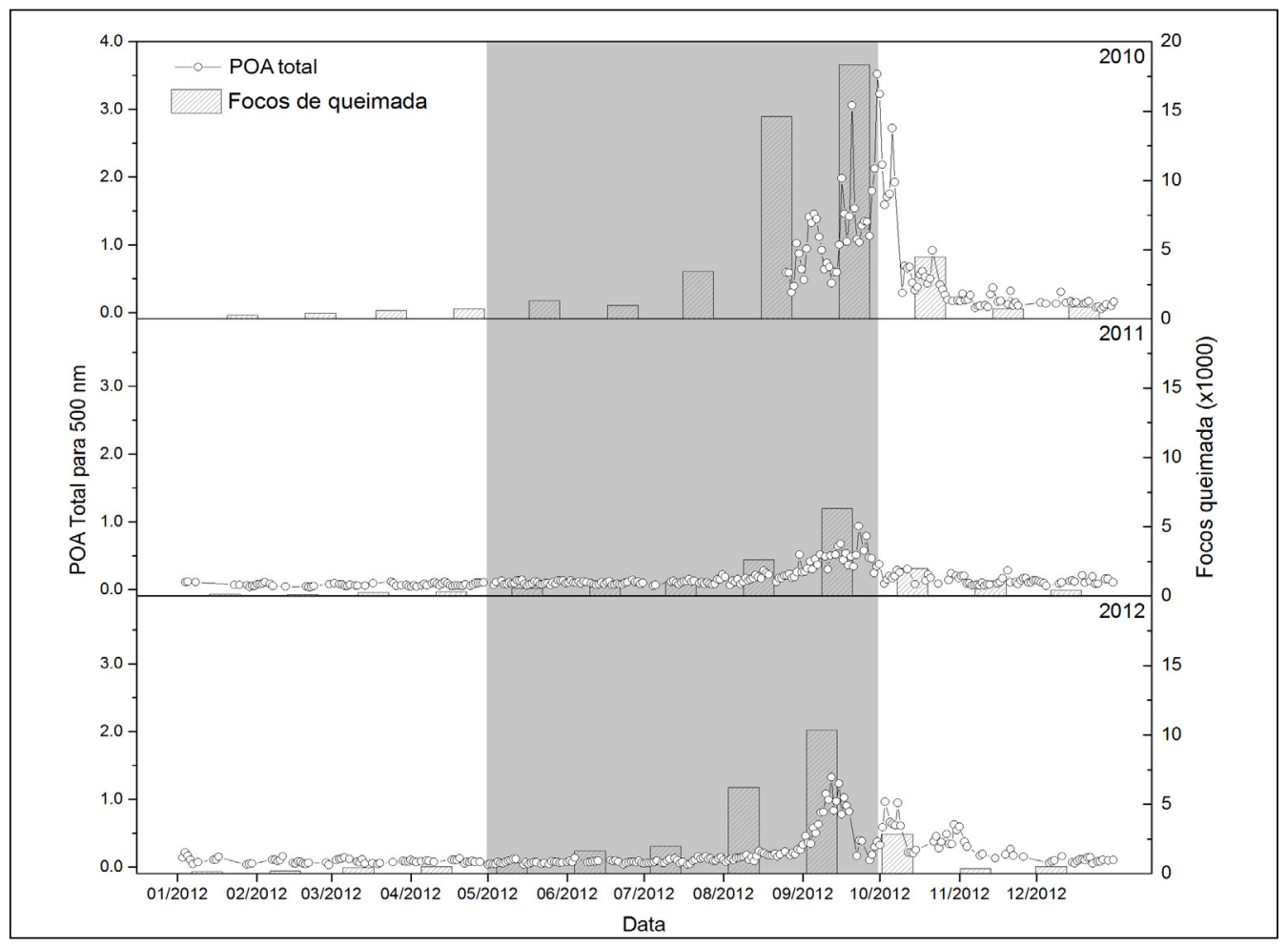


O maior valor para POA no ano de 2011 foi 0,9 e em 2012 foi de 1,3, registrado também no mês de setembro. Os valores de POA entre todos os anos estudados variaram entre 0,3 e 3,8 entre os meses de agosto, setembro e outubro. Valores similares para os anos de 2011 e 2012 foram encontrados por Palácios (2014), em pesquisa feita na mesma regiáo deste estudo, encontrou valores diários de aproximadamente 1,0 para POA, mostrando valores elevados, se comparados com Kumar et al. (2013), que em sua pesquisa desenvolvida na África do Sul, para uma região sub-tropical, encontraram média de 0,3 durante a primavera (setembro-novembro), e Forment (2002), que para uma região semi-árida na África, entre os anos de 1991 a 2001, encontrou médias de 0,44 entre os meses de agosto e setembro. $\mathrm{O}$ aumento da POA nos meses de agosto e setembro apresenta uma sazonalidade acentuada que está ligada à estaçáo de queima de biomassa no hemisfério Sul, sugerindo que as partículas de queimadas são transportadas pelos ventos alísios de Namíbia e Angola.

Procópio et al. (2004) e Wyrepkowski (2007) encontraram valores semelhantes durante o ano de 2001 na cidade Cuiabá - MT, com picos no mês de setembro, atingindo 1,57 em 2003 e chegando a média diária de 2,50 em setembro de 2002 e 2005. Desta forma nota-se uma modificação dos valores de POA entre as estaçóes chuvosa e seca. Quando há incidência de chuvas ocorre diminuiçáo de material particulado na atmosfera, determinando que os padróes de precipitaçáo influenciem nos valores da POA. Partículas na troposfera podem influenciar na quantidade de energia que chega até a superfície terrestre por meio do espalhamento e a absorção da radiação solar (ROCHA; YAMASOE, 2013).

A Figura 4 representa o gráfico de regressão linear entre a média diária de POA e a $\mathrm{R}_{\mathrm{g}}$ máxima diária das estaçóes secas para os anos de 2010, 2011 e 2012. 
Figura 4 - Regressão Linear entre a média diária da POA e a $\mathrm{R}_{\mathrm{g}}$ máxima diária para os períodos de seca nos anos de 2010, 2011 e 2012. Pontos representam dias disponíveis de dados na rede AERONET e com boas condiçóes meteorológicas (sem chuva e nebulosidade)

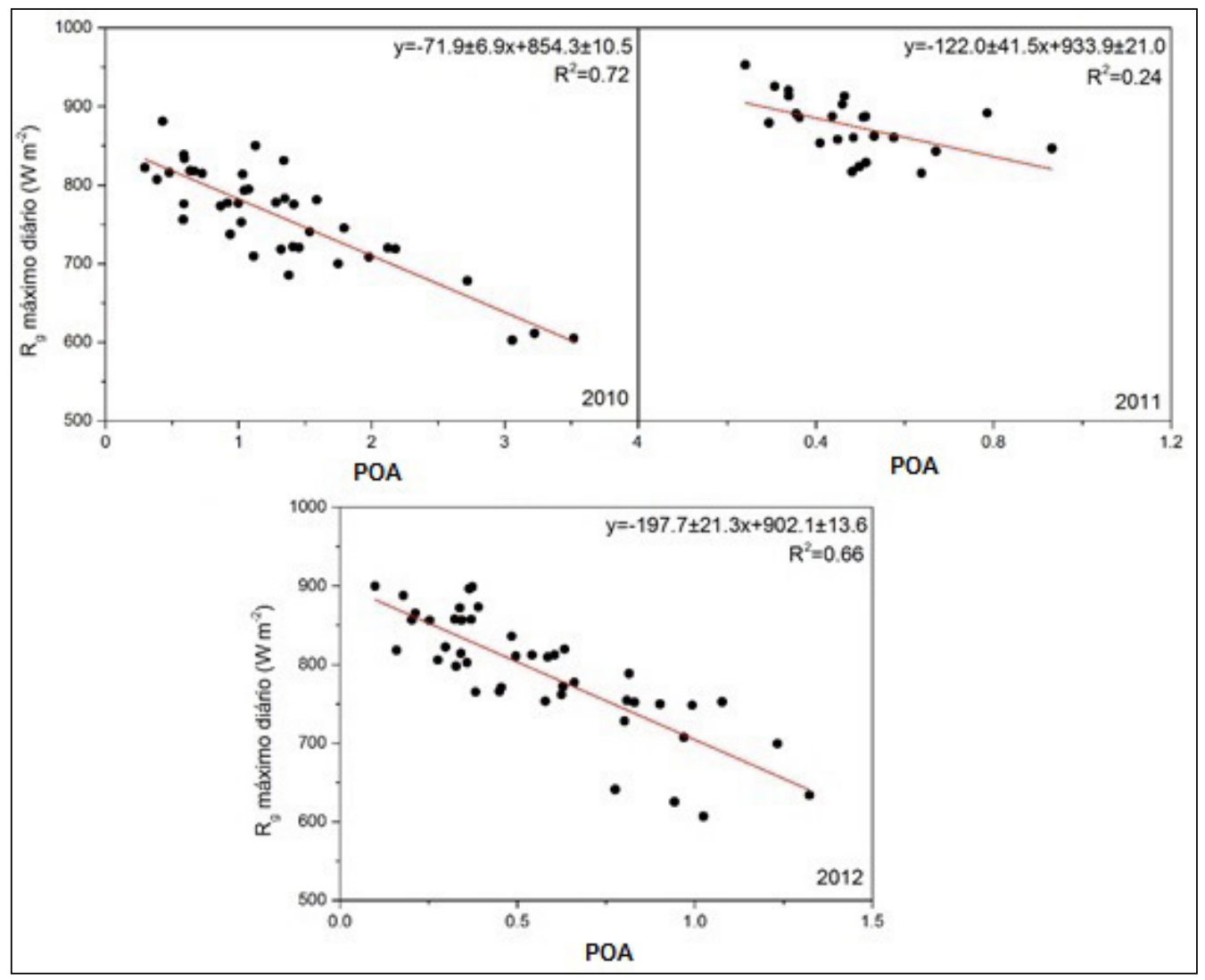

O valor do coeficiente de determinação obtido no ano de $2010\left(\mathrm{R}^{2}=0,72\right)$ e no ano de $2012\left(\mathrm{R}^{2}=0,66\right)$ indica relação entre as variáveis analisadas; quanto maior os valores da POA menor a quantidade de radiação incidente na superfície. À medida que o conteúdo de poluentes aumenta na atmosfera seja pela ação antrópica ou natural a concentração de partículas de fração fina torna-se mais concentrado nas camadas atmosféricas entre 1 e 2 $\mathrm{km}$, aumentando o valor da profundidade óptica dos aerossóis.

O valor do coeficiente de determinação obtido $\left(R^{2}=0,24\right)$ para o ano de 2011 indica uma baixa relação entre as variáveis analisadas. Esta relação entre as variáveis está associada à quantidade de radiação solar, assim quanto menor o valor da POA maior será a quantidade de energia disponível para o sistema. Procópio (2005), em sua pesquisa com dados obtidos pela rede AERONET observa que Cuiabá é um local de forte influência antropogênica. A alteração na quantidade de radiação disponível mostrou-se importante parâmetro na análise da distribuição de energia sobre a superfície, auxiliando nos mecanismos de troca radiativa entre a atmosfera e a superfície natural. 
A Figura 5 representa regressão linear entre a média diária da POA e o somatório da radiaçáo fotossinteticamente ativa diária para os anos de 2010, 2011 e 2012 e apresenta-se uma redução da radiação fotossinteticamente ativa (RFA), quando ocorreu um aumento da POA no mês de setembro, período em que ocorrem os altos índices de queimadas em MT (FIGURA 3).

Figura 5 - Regressão Linear entre a média diária da POA e o somatório da radiação fotossinteticamente ativa diária para os períodos de seca nos anos de 2010, 2011 e 2012. Pontos representam dias disponíveis de dados na rede AERONET e com boas condiçóes meteorológicas (sem chuva e nebulosidade)

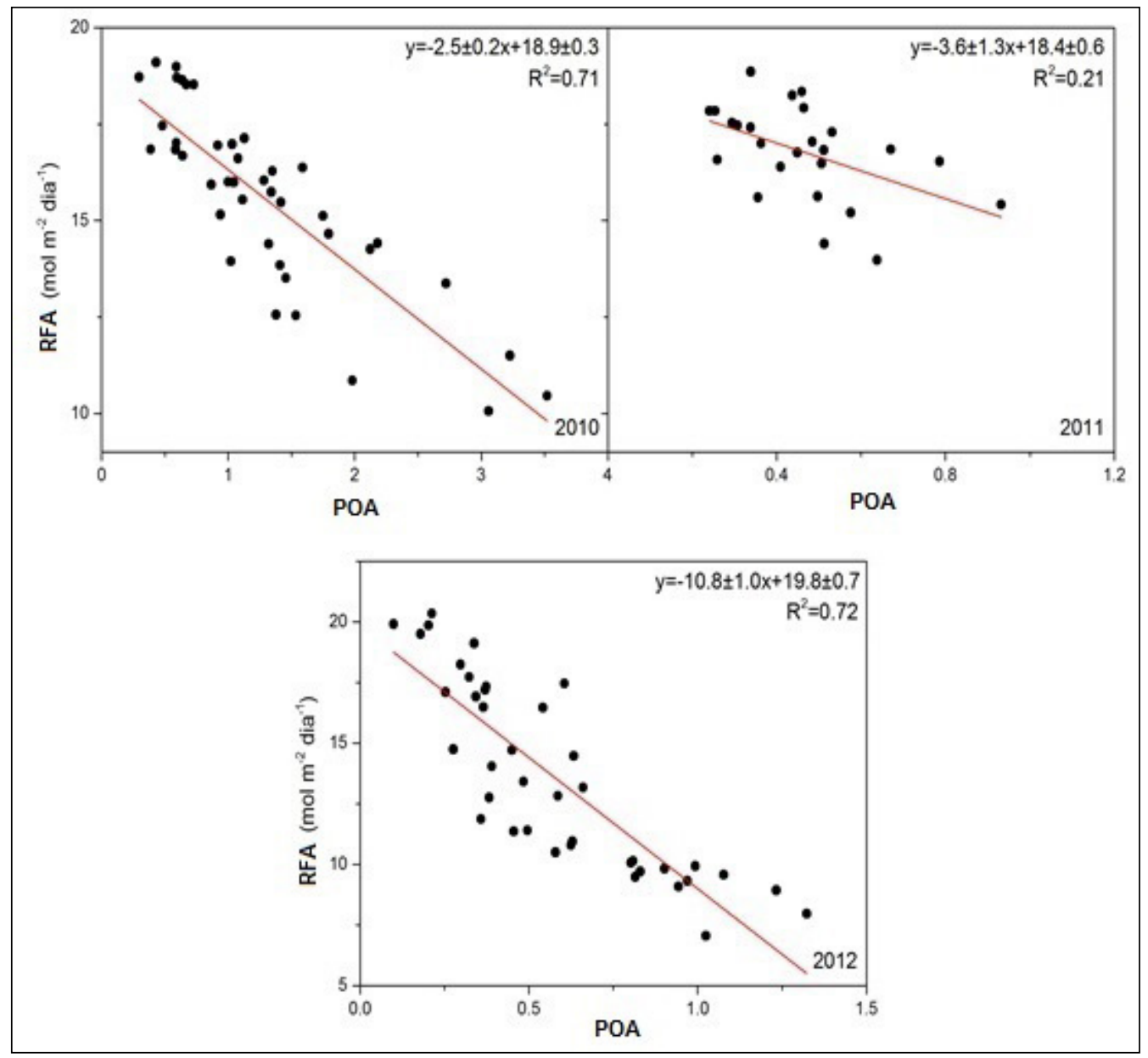

A disponibilidade de RFA é fundamental para a eficiência de fotossíntese das plantas, porém na estação seca aumenta a concentração de aerossóis de queimadas principalmente no mês de setembro conforme mostra a Figura 5, diminuindo a RFA pela interferência dessas partículas na atmosfera. 
Os valores diários da RFA foram monitorados no mês de setembro para todos os anos estudados e constatou-se que o coeficiente de determinaçáo foi maior nos anos de $2010(0,71)$ e $2012(0,72)$, época em que ocorreu um índice maior de queimadas na regiáo, conforme mostra a Figura 3. No ano de 2011 obteve-se menor valor de profundidade óptica o que explica o valor de coeficiente $\mathrm{R}^{2}$ ser menor que os demais anos estudados.

\section{CONCLUSÃO}

A pesquisa contribuiu quanto ao entendimento dos processos de transferências radiativas e suas influências no microclima local, em que para o ano de 2010, ano que ocorreu mais focos de incêndio para o período analisado, o coeficiente de determinaçáo $\mathrm{R}^{2}$ foi de 0,71 para radiação global e 0,72 para radiação fotossinteticamente ativa, indicando relação entre POA e a radiação. Constatou-se que as partículas de aerossóis predominam entre os meses da estaçáo seca, consequentemente maior POA, especialmente no mês de agosto e setembro pela contribuição do fenômeno natural da estiagem, aumento de focos de queimadas diminuindo assim a intensidade da radiação solar para o ambiente, provocando alteraçóes de sua distribuição no sistema superfície-atmosfera.

\section{REFERÊNCIAS}

ARTAXO, P. et al. Química atmosférica na Amazônia: A floresta e as emissóes de queimadas controlando a composição da atmosfera amazônica. Acta Amazonica. v. 35(2), p. 185-196, 2005.

ARTAXO, P. et al. Efeitos climáticos de partículas de aerossóis biogênicos e emitidos em queimadas na Amazônia. Revista Brasileira de Meteorologia, 2006.

CARRILHO SOBRINHO, F. J. Modelos para estimativa da radiaçáo de onda longa atmosférica no cerrado mato-grossense [Tese]. Cuiabá-MT, Programa de Pós Graduação em Física Ambiental, UFMT; 2011.

COUTINHO, L. M. Fire in the Tropical Biota-Ecosystem Processes and Global Challenges. J. G. Goldammer Editions - Ecological Studies, vol. 8A. Springer Verlag, Berlin, 1990.

DOUGHTY, C. E., FLANNER, M. G., GOULDEN, M. L. Effect of smoke on subcanopy shaded light, canopy temperature, and carbon dioxide uptake in an Amazon rainforest, Global Biogeochem. Cy., 24, GB3015, doi:10.1029/2009GB003670, 2010.

EMBRAPA. Sistema brasileiro de classificação de solos. Brasília: Embrapa, 472p. 1999.

HARRIS, D. A. Química Analítica Quantitativa. Rio de Janeiro: LTC, 2008.

HOLBEN, B.N. et al. AERONET: A federated instrument network and data archive for aerosol characterization. Remote Sensing Environment, 66, 1-16, 1998. 
FORMENTI, P. et al. Aerosol optical depth over a remote semi-arid region of South Africa from spectral measurements of the daytime solar extinction and the nighttime stellar extinction. Atmospheric Research, p. 11-32, 2002.

FROST, P. G. et al. Response of savannas to stress and disturbance. Biology International Special, Issue 10, IUBS, Paris, 1986.

KÖPPEN, W. Climatologia. México: Fondo de Cultura Económica, 1948.

KUMAR K. R. et al. Inferring wavelength dependence of AOD and Ångström exponent over a subtropical station in South Africa using AERONET data: Influence of meteorology, long-range transport and curvature effect. Science of the Total Environment, 461- 462, 397-408, 2013.

MONTGOMERY, R.A., CHAZDON, R.L. Forest structure, canopy architecture and light transmittance in tropical wet forests. Ecol. Eng. 82:2707-2718, 2001.

MOREIRA, A.F., SANTOS, S.R.B., COSTA JUNIOR, A. G. Construção e caracterização de um fotômetro destinado ao uso de aulas experimentais de química sobre a lei de Beer-Lambert. HOLOS, ano 32, v.2, 2016.

NOVAIS, J.W.Z. et al. Conforto térmico de um laboratório da Universidade de CuiabáMT UNIC. Revista eletrônica em gestáo, educaçáo e tecnologia ambiental. v.19, n.3, p. 804-812, 2015a.

NOVAIS, J. W. Z. et al. Variação horária e sazonal da radiação solar incidida e refletida e suas relaçóes com variáveis micrometeorológicas no Pantanal Norte Mato-grossense.

Revista Brasileira de Ciências Ambientais, n.38, p. 96-108, 2015 b.

NOVAIS, J. W. Z. et al. Albedo do solo abaixo do dossel em área de Vochysia Divergens Pohl no norte do Pantanal. Revista Brasileira de Meteorologia, v. 31, n.2., 157-166, DOI: http://dx.doi.org/10.1590/0102-778631220150001, 2016.

OLIVEIRA, P. H. F. et al. The effects of biomass burning aerossol and clouds on the $\mathrm{CO} 2$ flux in Amazonia, Tellus B, 59, 338-349, 2007.

PALÁCIOS, R.S. Análise da profundidade ótica de aerossóis no cerrado matogrossense. [Dissertação]. Cuiabá-MT, Programa de pós-graduação em Física Ambiental, Universidade Federal de Mato Grosso, 2014.

PERON, A. J.; EVANGELISTA, A. R. Degradação de pastagens em regióes de cerrado. Ciência e Agrotecnologia. Lavras, v. 28, n. 3, p. 655-661, 2004.

PROCOPIO, A.S. Forçante Radiativa Direta dos Aerossóis na Regiáo Amazônica

Devido a Queima de Biomassa [Tese]. São Paulo-SP, Instituto de Astronomia, Geofísica e Ciências Atmosféricas da Universidade de São Paulo, 2005. 
PROCOPIO, A. S. et al. Multiyear analysis of amazonian biomass burning smoke radiative forcing of climate. Geophysical Research Letters, v. 31, L03108, doi:10.1029/2003GL018646, 2004.

RAP, A. et al. Fires increase Amazon forest productivity through increases in diffuse radiation, Geophys. Res. Lett., 42, 4654-4662, doi:10.1002/2015GL063719, 2015.

REDDINGTON, C. et al. Analysis of partículate emissions from tropical biomass burning using aglobal aerossol model and long-term surface observations. Atmospheric Chemitry and Physics, 16, 11083-11106, 2016

REZENDE, A. V. SANQUETTA, C. R.; FIGUEIREDO FILHO, A. Efeito do desmatamento no estabelecimento de espécies lenhosas em um cerrado Sensu stricto. Floresta, Curitiba, PR, v.35, n. 1, jan./abr. 2005.

RODRIGUES, T. R. et al. Seasonal variation in energy balance and canopy conductance for a tropical savanna ecosystem of south central Mato Grosso, Brazil, Journal of Geophysical Research: Biogeosciences, vol. 119, 1-13, doi:10.1002/2013JG002472, 2014.

ROCHA, V. R., YAMASOE M. A., Estudo da Variabilidade Espacial e Temporal da Profundidade Óptica do Aerossol obtida com o Modis sobre a regiāo Amazônica. Revista Brasileira de Meteorologia, v.28, n.2, 210 - 220, 2013.

SAMPAIO, M.M.A. Análise do desempenho térmico e lumínico de habitaçóes populares em Cuiabá-MT [dissertação]. Cuiabá-MT, Programa de pós-graduação em Física Ambiental, Universidade Federal de Mato Grosso, 2006.

SILVA JR. R. S., ANDRADE, M. F. Validação de poluentes fotoquímicos e inclusão do inventário de emissóes no modelo de qualidade do ar wrf/chem, para a regiáo metropolitana de São Paulo. Revista Brasileira de Meteorologia, v.28, n.1, 105 - 121, 2013.

SILVA, J. E. DA; RESCK, D. V. S.; CORAZZA, E. J.; VIVALDI, L. Carbon storage in clayey Oxisol cultivated pastures in the "Cerrado" region, Brazil. Agriculture, Ecosystems and Environment, v.103, p. 357-363. 2004.

SILVA, L. C. R. Dinâmica de transição e interaçóes entre fitofisionomias florestais e formaçóes vegetacionais abertas do bioma Cerrado [dissertação]. Brasília-DF. Mestrado em Ciências Florestais, Departamento de Engenharia Florestal, Universidade de Brasília, 2007.

YAMASOE, M. A.; VON RANDOW, C.; MANZI, A. Effect of Smoke on the Transmissivity of Photosynthetically Active Radiation Inside the Canopy. Atmospheric Chemistry and Physics Discussions, Alemanha, v. 6, p. 1646-1656, 2006. 
YAMASOE, M. A. ; ROSARIO, N. M. E. Changes in solar radiation partitioning reaching the surface due to biomass burning aerosol particles in the Amazon Basin. In: International Radiation Symposium - IRS2008, Foz do Iguaçu. Current Problems in Atmospheric Radiation (IRS2008) Proceedings of the International Radiation Symposium (IRC/IAMAS). Melville, New York : American Institute of Physics, 2008. v. 110. p. 657-660, 2009.

WALKER, B. H., NOY-MEIR, I. Aspects of the stability and resilience of savanna ecosystem. Ecology of tropical savannas. p. 556-590, Springer, Berlin, 1982.

YÁNEEZ-SERRANO, A. M. et al. Atmospheric mixing ratios of methyl ethyl ketone (2-butanone) in tropical, boreal, temperate and marine environments. Atmospheric Chemistry and Physics, 16, 10965-10984, 2016. 